\title{
Short-term storage of semen samples in acidic extender increases the proportion of females in pigs
}

\author{
Yoo-Jin Park, Dong-Ha Shin, Won-Ki Pang, Do-Yeal Ryu, Md Saidur Rahman, Elikanah Olusayo Adegoke and \\ Myung-Geol Pang*
}

\begin{abstract}
Background: Sex preselection is a desired goal of the animal industry to improve production efficiency, depending on industry demand. In the porcine industry, there is a general preference for pork from female and surgically castrated male pigs. Therefore, the birth of more females than males in a litter leads to economic benefits and improved animal welfare in the pig production industry. Our previous study suggested that the porcine semen extender (BTS) adjusted to pH6.2 maximises the differences in viability between $X$-chromosome-bearing $(X)$ spermatozoa and Y-chromosome-bearing $(Y)$ spermatozoa without affecting sperm's functional parameters. In this study we aimed to evaluate whether the pH6.2 extender is applicable at the farm level for increasing the number of female piglets without a decline in spermatozoa fertility. Artificial insemination (Al) was carried out with spermatozoa stored at pH6.2 and pH7.2 (original BTS) at day 1 and day 2 of storage. Next, the functional parameters of the spermatozoa, litter size, farrowing rate, and female-to-male ratio of offspring were determined.

Results: Although sperm motility decreased significantly after $2 \mathrm{~d}$ of storage, the viability of spermatozoa was preserved at pH6.2 for $3 \mathrm{~d}$. There was no significant difference in the farrowing rate and average litter size between the group inseminated with the spermatozoa stored in $(\mathrm{pH} 7.2)$ and that inseminated with spermatozoa stored in acidic BTS. The percentage of female piglets was approximately 1.5 -fold higher in sows inseminated on day 1 in the pH6.2 than in the pH7.2 group. Furthermore, although there was no significant difference in the female-to-male ratio, the percentage of female piglets born was slightly higher in the pH6.2 group than in the pH7.2 group on day 2 .
\end{abstract}

Conclusions: The method optimised in our study is simple, economical, and may enhance the number of female births without any decline in spermatozoa fertility.

Keywords: Artificial insemination, Boar spermatozoa, Acidic semen extender, Sex ratio, Sex preselection

\section{Background}

In the livestock production industry, sex preselection is desirable to improve reproductive efficiency for specialised purposes such as milk production, breeding for artificial insemination (AI), and meat production. Pork

\footnotetext{
*Correspondence: mgpang@cau.ac.kr

Department of Animal Science \& Technology and BET Research Institute, Chung-Ang University, 4726 Seodong-daero, Deadeok-myon, Anseong, Gyeonggi-do 17546, Republic of Korea
}

production relies on meat from female and castrated pigs rather than that from boars, despite the cost-effectiveness of raising entire boars due to their higher feed conversion efficiency and growth rate, because $5-10 \%$ of the meat from boars has an unpleasant meat taint, which affects meat acceptability [1]. As surgical castration is a debatable option in terms of animal welfare, alternatives to castration or a new technique for producing a higher number of females is required [2]. Over the past decades, several methods based on nutrition, weather, 
stress, hormone levels, insemination time, and location of insemination in the female reproductive tract have been used to manipulate the sex ratio of offspring; however, the efficiency of sex preselection using these methods remains debatable [3-6]. Recently, AI was performed using sexed spermatozoa or embryos sorted by flow cytometry, which showed more than $90 \%$ accuracy in sex preselection [7, 8]. Although this method can produce the desired offspring with high probability, it has some limitations for field applications such as low sperm concentration for boar AI and severe damage to cells during the staining and sorting procedures [9]. Furthermore, this method requires expensive equipment and skilled experts [10]. Therefore, the development of simple and inexpensive methods for the preselection of porcine offspring at the farm level is required to enhance profits in the pig industry.

Previously, we have reported that Y-chromosome-bearing $(\mathrm{Y})$ spermatozoa are more susceptible to stress, such as endocrine disruptors, $\mathrm{pH}$, incubation time, and temperature, compared to the X-chromosome-bearing (X) spermatozoa in humans and mice [11-14]. We also found that the $\mathrm{X}: \mathrm{Y}$ ratio of live porcine spermatozoa stored in the acidic (pH6.2) porcine semen extender (BTS) for $2 \mathrm{~d}$ was maximised without affecting the intrinsic fertilising ability of spermatozoa [15]. However, no effort has been made to integrate this process at the farm level. Therefore, in this study we aimed to evaluate whether this modified acidic BTS can be applied to porcine AI techniques at the farm level to increase the number of female piglets without negative fertility outcomes.

\section{Results}

\section{Effect of $\mathrm{pH}$ on sperm functional parameters}

To evaluate the changes in sperm functional ability in the pH7.2 and pH6.2 semen samples after $3 \mathrm{~d}$, sperm viability, motility, and motion kinematics were evaluated. Sperm motility decreased drastically after day 2 at $\mathrm{pH} 6.2(p<0.05)$, whereas there was no significant change at $\mathrm{pH} 7.2$ on $3 \mathrm{~d}$. Therefore, motility was lower at pH6.2 than that at pH7.2 (Fig. 1A, $p<0.05$ ). HYP was identified as spermatozoa have curvilinear velocity $(\mathrm{VCL})>80 \mu \mathrm{m} / \mathrm{s}$, linearity $(\mathrm{LIN})<65 \%$, and an amplitude of lateral head displacement $(\mathrm{ALH})>6.5 \mu \mathrm{m}$. There was no significant difference in HYP in either group over $3 \mathrm{~d}$ (Fig. 1B). Straight line velocity (VSL) significantly declined from day 2 at $\mathrm{pH} 6.2$, whereas VSL decreased from day 3 at pH7.2. The VSL was significantly lower at pH6.2 than that at pH7.2 after day 3 (Fig. $1 \mathrm{C}, p<0.05$ ). Although VCL decreased significantly from day 2 at pH6.2 $(p<0.05)$, there was no difference between pH6.2 and $\mathrm{pH} 7.2$ during the $3 \mathrm{~d}$ (Fig. 1D). Although the average path velocity (VAP) of spermatozoa decreased significantly from day 2 at $\mathrm{pH} 6.2$, a significant decline was observed from day 3 at pH7.2 $(p<0.05)$. On day 3 , the VAP of spermatozoa at $\mathrm{pH} 6.2$ was significantly lower than that of spermatozoa at pH7.2 (Fig. 1E, $p<0.05$ ). While the LIN was significantly declined from day 3 at $\mathrm{pH} 6.2$, there was no difference in $\mathrm{pH} 7.2$ for 3 days (Fig. 1F). Consequently, LIN was significantly lower at pH6.2 than that at pH 7.2 after day 3 (Fig. 1F). The VCL decreased significantly from day 2 at $\mathrm{pH} 6.2$, whereas no differences were detected at $\mathrm{pH} 7.2$ for 3 days (Fig. 1G).

The changes in live/dead spermatozoa were not significant in either group and there was also no difference in these changes between the groups (Fig. 2).

There were no significant differences in intracellular ATP and mitochondrial membrane potential (MMP) in either $\mathrm{pH}$ group over $3 \mathrm{~d}$ (Fig. $3 \mathrm{~A}$ and $\mathrm{B}$ ), whereas ROS levels decreased drastically from day 2 in both $\mathrm{pH}$ groups (Fig. 3C).

\section{Acidic semen samples increased the number of female births without adverse fertility}

To evaluate whether the use of the acidic semen samples is applicable at the farm level to increase the number of female births without fertility decline, we examined the farrowing rate, total litter size, and the female-to-male ratio. The farrowing rate was calculated as the total number of inseminated sows divided by the total number of farrowed sows in each group. In the sows inseminated on day 1 , the farrowing rates were 88.31 and $83.75 \%$ for the $\mathrm{pH} 7.2$ and $\mathrm{pH} 6.2$ groups, respectively, and there was no significant difference between the two groups (Fig. 4A). In sows inseminated on day 2, the farrowing rate of the $\mathrm{pH} 6.2$ group (95.51\%) was significantly higher than that of the pH7.2 group (83.13\%) (Fig. 4A, $p<0.01$ ). The acidic semen sample was not observed to have any effect on the litter size. The average litter size of the sows inseminated on day 1 was 11.29 and 11.40 in the $\mathrm{pH} 7.2$ and 6.2 groups, respectively. In sows inseminated on day 2 , the average litter size was 11.66 and 11.36 in the pH7.2 and 6.2 groups, respectively (Fig. 4B). Furthermore, to determine the efficacy of acidic semen samples in producing female piglets, we analysed the relative ratio of female-to-male offspring in each group. It is noteworthy that the relative ratio of female piglets in the $\mathrm{pH} 6.2$ group (146.83\%) inseminated on day 1 was approximately 1.5-fold higher than that in the $\mathrm{pH} 7.2$ group inseminated the same day $(p<0.001$, Fig. $4 \mathrm{C})$. Although there was no significant difference between the pH7.2 and 6.2 groups inseminated on day 2 , the relative ratio of female piglets in the litter was still higher in the pH6.2 group (118.43\%) than in the $\mathrm{pH} 7.2$ group (Fig. 4C). In sows inseminated on day 1 , the male ratio (5.5) was significantly higher than the female ratio (4.5) in the $\mathrm{pH} 7.2$ group $(p<0.001)$, 


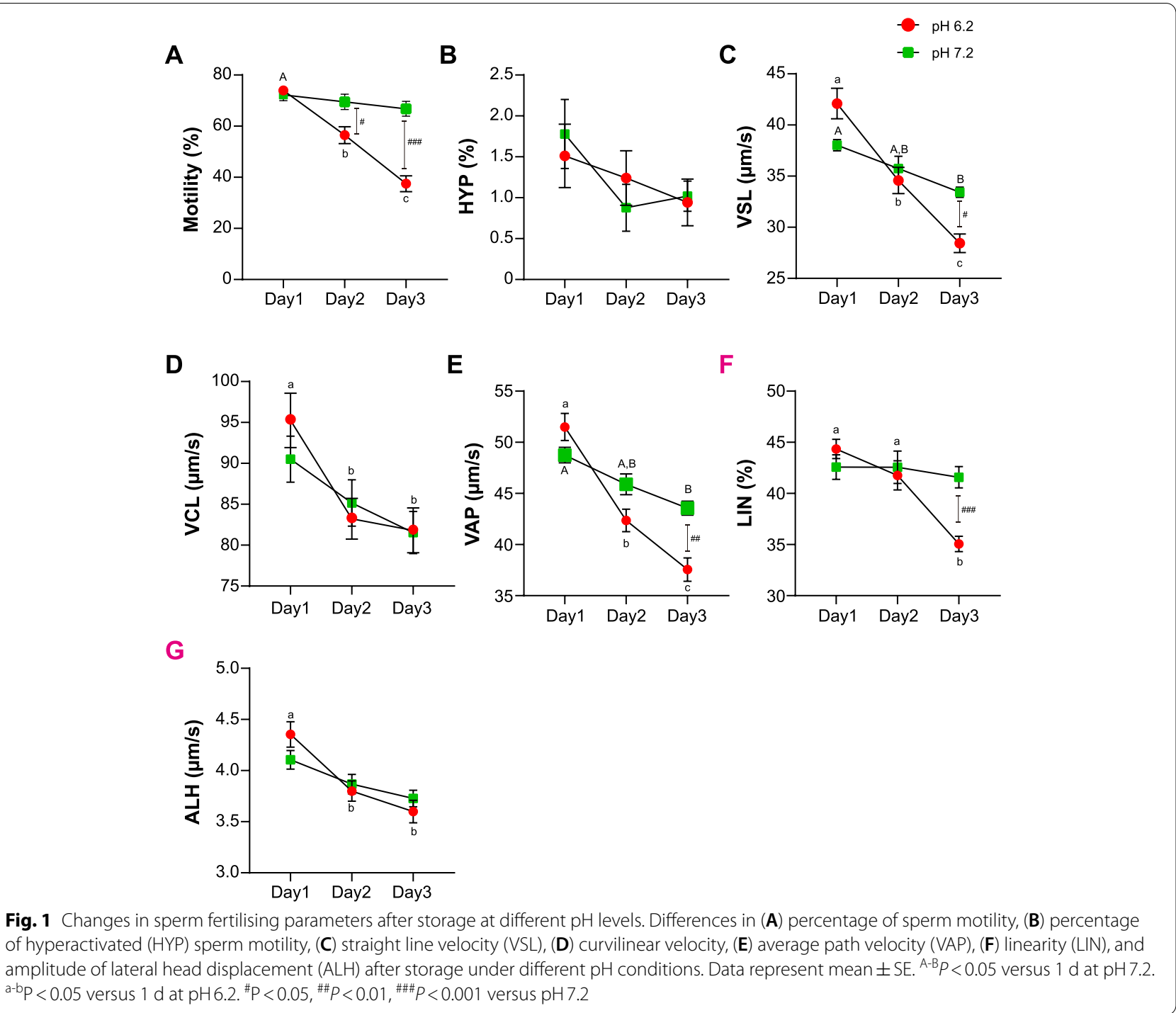

A

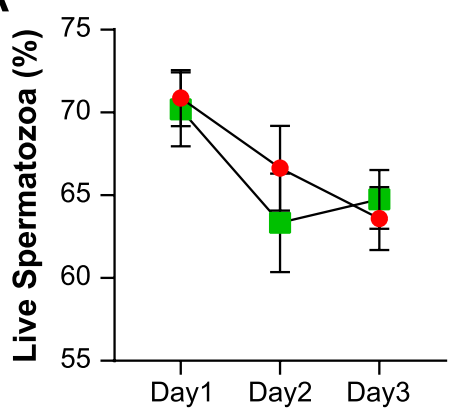

B

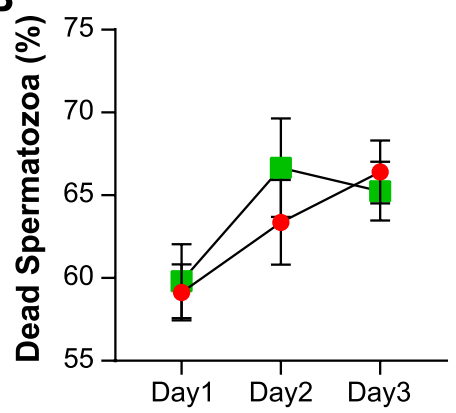

Fig. 2 Changes in viability of spermatozoa during storage at different pH levels. Percentage of (A) live and (B) dead spermatozoa during storage at different $\mathrm{pH}$ levels. Data represent mean $\pm \mathrm{SE}$ 
A

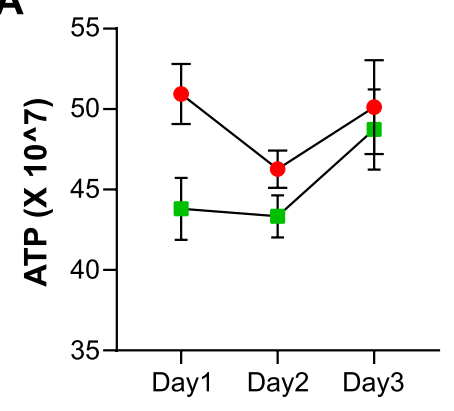

C

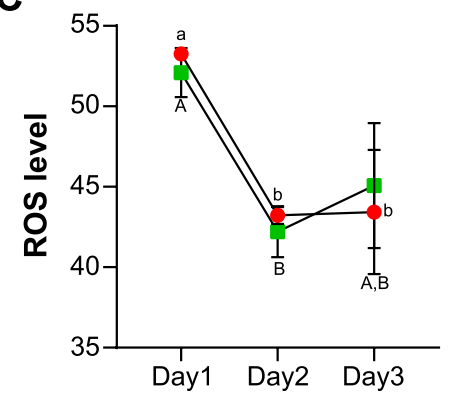

B
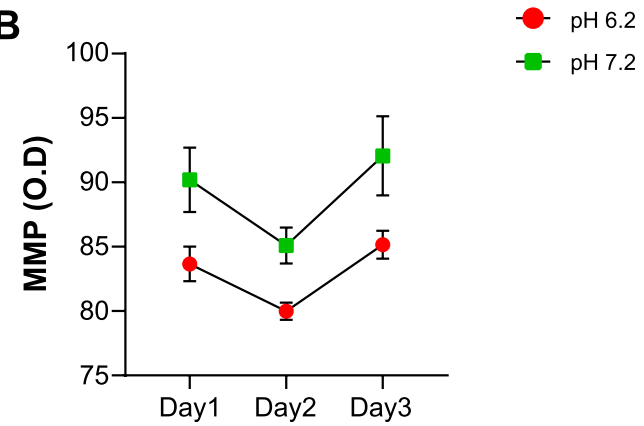

Fig. 3 Effect of different pH levels on sperm functional parameters. Changes in (A) intracellular ATP, (B) mitochondrial membrane potential (MMP), and $(\mathbf{C})$ intracellular reactive oxygen species (ROS) levels of spermatozoa stored at different pH levels. Data represent mean $\pm \mathrm{SE}$. ${ }^{\mathrm{a}-\mathrm{b}} \mathrm{P}<0.05$ versus 1 d at $\mathrm{pH} 6.2$

A

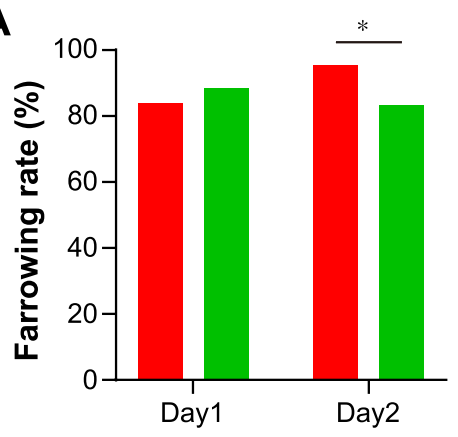

C

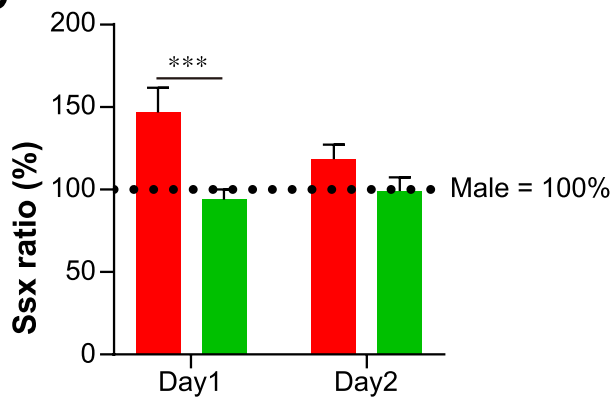

B

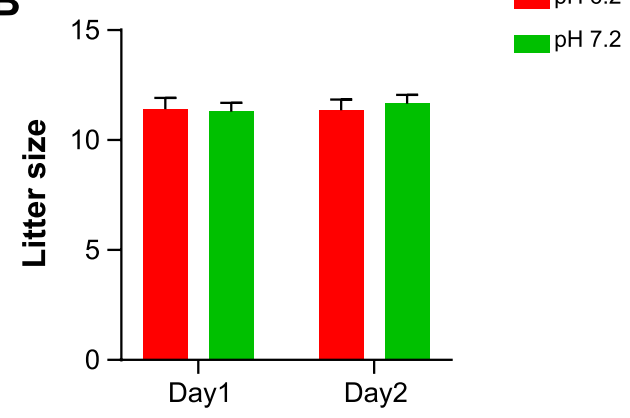

Fig. 4 Effect of different pH levels on in vivo fertility of pig spermatozoa. Changes in the (A) farrowing rate, (B) litter size, and (C) relative female-to-male ratio after insemination with spermatozoa stored at different $\mathrm{PH}$ levels. Data represent mean $\pm \mathrm{SE} .{ }^{* *} \mathrm{P}<0.01,{ }^{* * *} \mathrm{P}<0.001$ versus $\mathrm{pH} 7.2$ 
whereas the female ratio (5.3) was significantly higher than the male ratio $(4.7)$ in the $\mathrm{pH} 6.2$ group $(p<0.01)$ (Table 1). The female-to-male ratio at $\mathrm{pH} 6.2$ in sows inseminated on day 2 was 5:5; however, the male ratio was significantly higher than the female ratio at $\mathrm{pH} 7.2$ on day 2 (45\%: $55 \%$, Table $1, p<0.001)$. In addition, the number of male piglets (5.3) was significantly higher than that of female piglets (6.0) at pH7.2 after $2 \mathrm{~d}$ (Table 1, $p<0.05)$. Although there was no significant difference between the pH7.2 and 6.2 groups inseminated on day 2 , the relative ratio of female piglets in the litter was still higher in the pH6.2 group (118.43\%) than that in the pH7.2 group (Fig. 4C and Table 1).

\section{Discussion}

Sex preselection in livestock production can improve production efficiency and provide economic benefits at the farm and industry levels. In pork meat production, although feed efficiency, growth rate, and carcass quality of the entire boar are better than those of female or castrated pigs, boars are avoided as they have a boar taint, which is the reason for an objectionable odour and taste in meat $[16,17]$. Due to the increasing concerns about animal welfare, some countries have banned surgical castration without anaesthesia [18]. Therefore, producing a higher number of females than males would result in a reduction in the extra cost for castration and have a positive impact on animal welfare $[19,20]$. Over the last decades, sexed spermatozoa sorted by flow cytometry according to DNA content are preferred for AI to generate the desired offspring with high accuracy [21, 22]. Generally, spermatozoa sorted by flow cytometry are stored as frozen semen samples with a small number of spermatozoa. However, this method is not applicable to porcine AI because a large number of spermatozoa per dose are required for AI and the poor quality of spermatozoa obtained after the freeze-thawing process [10]. Furthermore, the cost of equipment is one of the limitations of using this technique at the farm level [2]. Therefore, the development of a new and more efficient and simplified method for sex preselection is needed.

Our previous studies have demonstrated that $\mathrm{X}$ spermatozoa survive functionally longer than $\mathrm{Y}$ spermatozoa under stress conditions such as chemical exposure, temperature, and $\mathrm{pH}$ in mice and humans [11-13]. Both in previous [15] and this study, approximately $50 \mu \mathrm{L}$ of $30 \% \mathrm{HCl}$ was added into extended semen samples directly to adjust pH6.1 to 6.2 for minimizing the detrimental effects during additional semen sample preparation procedure such as centrifugation and equilibration with new extender. We found that there were no differences in quantity (ATP concentration, MMP, and ROS) and quality of semen samples (farrowing rate and litter size) between control and acidic semen samples. These results indicate that direct addition of small amount of $30 \% \mathrm{HCl}$ in the semen samples could not be quite detrimental for sperm cells. In addition, we found that the X:Y ratio of live spermatozoa in an acidic boar semen sample (pH 6.2) was maximised at 1.2:1 without a negative effect on sperm quality, such as sperm motility, viability, and capacitation status [15]. Moreover, we assessed the expression level of fertility-related biomarkers to determine the effect of storage at different $\mathrm{pH}$ on the male fertility [23-25]. There were no differences of protein and mRNA expressions during storage at different $\mathrm{pH}$ conditions. The production of female offspring may increase when acidic BTS is used for at least 2 days without negative effects on sperm fertility [15]. Based on our previous studies, we tried to confirm whether the acidic semen samples can enhance female production at the farm level. To obtain reasonable AI results, more than 300 sows were inseminated with acidic and original semen samples for $2 \mathrm{~d}$. Although sperm motility, VSL, and VAP were significantly lower in acidic semen samples than in the original semen samples, no differences in the percentage of live spermatozoa were detected. Furthermore, there was no reduction in farrowing rate and litter size following AI using acidic semen samples compared to the original

Table 1 Number of male and female piglets and sex ratio after artificial insemination

\begin{tabular}{|c|c|c|c|c|c|}
\hline & & \multicolumn{2}{|l|}{$\mathrm{pH} 7.2$} & \multicolumn{2}{|l|}{$\mathrm{pH} 6.2$} \\
\hline & & Female & Male & Female & Male \\
\hline \multirow[t]{2}{*}{ Day 1} & No. of piglets & $5.29 \pm 0.30^{\mathrm{a}}$ & $6.04 \pm 0.22$ & $5.88 \pm 0.31$ & $5.45 \pm 0.37$ \\
\hline & Ratio (\%) & $44.84 \pm 1.78^{* * *, b}$ & $55.16 \pm 1.78^{b}$ & $53.24 \pm 1.80^{\mathrm{a}}$ & $46.76 \pm 1.80$ \\
\hline \multirow[t]{2}{*}{ Day 2} & No. of piglets & $5.31 \pm 0.26^{\mathrm{a}}$ & $6.32 \pm 0.30$ & $5.66 \pm 0.32$ & $5.70 \pm 0.29$ \\
\hline & Ratio (\%) & $44.88 \pm 1.96^{* * *}$ & $55.12 \pm 1.96$ & $49.84 \pm 1.72$ & $50.16 \pm 1.72$ \\
\hline
\end{tabular}

${ }^{a}$ Significant difference between female and male within a row at $\mathrm{pH} 7.2$ and $\mathrm{pH} 6.2$, respectively. ${ }^{*} p<0.05 ;{ }^{* * *} p<0.001$

${ }^{\mathrm{b}}$ Significant difference in female ratios within a row between the $\mathrm{pH} 7.2$ and $\mathrm{pH} 6.2$ groups

Number of piglets indicates the average number of piglets per litter

Ratio (\%) indicates the average of sex ratio per sows 
semen sample over $2 \mathrm{~d}$. These results are in accordance with our previous report suggesting that viability can be maintained in acidic conditions without a decline in intrinsic sperm fertility [15]. Based on these results, we hypothesise that the fertilising ability of spermatozoa can be maintained in acidic semen samples similar to those in the epididymis that maintain quiescence in acidic conditions to prevent energy consumption before fertilisation [26]. Moreover, You et al. [11] found that more timedependent increase in apoptosis and DNA damage in the $\mathrm{Y}$ spermatozoa under stress condition, such as alkaline $\mathrm{pH}$, compared to those of $\mathrm{X}$ spermatozoa. Thus, we suggest that $\mathrm{Y}$ spermatozoa may have more vulnerable to acidic stress than $\mathrm{X}$ spermatozoa leads to increase the fertilization chance of X spermatozoa. Interestingly, our previous in vitro study showed that the $\mathrm{X}: \mathrm{Y}$ ratio of live spermatozoa in acidic semen samples was 1.2:1 on day 1 . We found that the number of female piglets was approximately 1.5- and 1.2-fold higher than that of male piglets from sows inseminated on days 1 and 2, respectively. These results may indicate that more $\mathrm{X}$ spermatozoa can survive and be selected during transit in the female reproductive tract than $\mathrm{Y}$ spermatozoa following stress exposure [27]. Moreover, these results indicated that overall fertility following the gender preselection by the decrease in the one sperm population could not effected.

\section{Conclusions}

We hypothesise that a sufficient number of X spermatozoa for AI may present and maintain fertility in acidic semen samples, whereas stress selectively decreases $\mathrm{Y}$ spermatozoa. Altogether, we propose that our modified boar semen sample is simple, economical, and may enhance the productivity of female piglets at the farm level. However, as sperm fertility can only be maintained for $2 \mathrm{~d}$, a more stable method is required for long-term storage without affecting the intrinsic fertility of the samples.

\section{Methods}

\section{Ethical statement}

All procedures were performed according to the guidelines for the ethical treatment of animals approved by the Institutional Animal Care and Use Committee of ChungAng University, Seoul, Korea.

\section{Sample preparation}

Boar semen samples were purchased from Darby Genetics Inc. (Anseong, Gyeonggi-Do, Republic of Korea). Boars were housed in individual pens at $20 \pm 5^{\circ} \mathrm{C}, 2: 1$ light/dark cycle with continuous air circulation system. The boars were fed a commercial feeding mixture according to the nutritional requirements for male boars and free access to water. Semen samples were collected from sexually matured Duroc boars (11 to 23 months, $>90 \mathrm{~kg}$ body weight) using the gloved-hand method and diluted in the Beltsville thawing solution. To eliminate individual differences, three to four boar semen samples were pooled and used for evaluation of sperm functional parameters and fertility. Non-treated pooled semen samples were used as control (pH 7.2) and $\mathrm{pH}$ of acidic semen samples was adjusted to $\mathrm{pH} 6.2$ by $30 \%$ of hydrochloric acid. The $\mathrm{pH}$ of control and acidic semen samples was evaluated before analysis and AI during 3 days using $\mathrm{pH}$ meter (Bante, China). The average $\mathrm{pH}$ of acidic semen samples was $6.13 \pm 0.07$ at day $1,6.16 \pm 0.06$ at day 2 , and $6.22 \pm 0.08$, respectively. And the average $\mathrm{pH}$ of control semen samples was $7.22 \pm 0.01$ at day $1,7.23 \pm 0.03$ at day 2 , and $7.23 \pm 0.01$, respectively. Following day 1 , day 2 , and day 3 incubation at $17^{\circ} \mathrm{C}$, sperm functional parameters were evaluated $(n=8)$. For artificial insemination, pooled semen samples divided into three to four vials according to number of sperm cells $\left(30 \times 10^{8} / 100 \mathrm{~mL}\right)$. Total twenty boars were used for the insemination.

\section{Sperm viability, motility, and motion kinematics}

Generally, HOST is used to evaluate the functional integrity of the sperm plasma membrane, it can be used as the viability test because membrane intact spermatozoa have a positive hypo-osmolar swelling reaction that indicate viable spermatozoa [28]. To analyse the viability of spermatozoa at different $\mathrm{pH}$ levels, a hypo-osmotic sperm swelling test (HOST) was used as explained in our previous study [29]. In brief, the sperm samples were incubated in the HOST solution (distilled water: $0.9 \% \mathrm{w} / \mathrm{v}$ $\mathrm{NaCl}$ [1:1], $150 \mathrm{mOsm} / \mathrm{kg}$ ) for $30 \mathrm{~min}$ at $37^{\circ} \mathrm{C}$. Next, the sperm suspension was smeared onto a glass slide, airdried, and fixed in a fixative containing 30\% methanol and $10 \%$ acetic acid in distilled water. Approximately, 500 sperm cells were analysed in random fields for each sample.

Sperm motility and motion kinematics were determined using computer-assisted sperm analysis (CASA) (SAIS-PLUS version 10.1; Medical Supply, Seoul, Korea) as previously described [30].

\section{Intracellular ATP}

Intracellular ATP was determined using an ATP Bioluminescence Assay Kit HS II according to the manufacturer's instructions (Roche Molecular Biochemicals, Mannheim, Germany). In brief, $25 \mu \mathrm{L}$ of a semen sample $\left(1 \times 10^{8}\right.$ sperm cells $/ \mu \mathrm{L}$ ) was added to a 96 -well plate, followed by $25 \mu \mathrm{L}$ of lysis buffer, and incubated for $5 \mathrm{~min}$ at room temperature. Next, $50 \mu \mathrm{L}$ of luciferase reagent was added and ATP bioluminescence intensity was determined using a 
microplate reader (GloMax-Multi Microplate Multimode Reader; Promega, Madison, WI, USA).

\section{Mitochondrial activity}

Mitochondrial membrane potential (MMP) was measured using JC-1 mitochondrial membrane potential assay kit according to manufacturer's instruction (Abcam, Cambridge, MA, USA). Briefly, spermatozoa were washed with modified TCM 199 (Sigma, St. Louis, MO, USA) medium containing $10 \%$ fetal bovine serum, $0.91 \mathrm{mM}$ sodium pyruvate, $3.05 \mathrm{mM}$ D-glucose, $2.92 \mathrm{mM}$ calcium lactate, and $2.2 \mathrm{~g} / \mathrm{L}$ sodium bicarbonate (mTCM 199) at $100 \times \mathrm{g}$ for $10 \mathrm{~min}$. Next, spermatozoa were incubated with mTCM 199 containing $1 \mu \mathrm{M} \mathrm{JC}-1$ for $30 \mathrm{~min}$ at $37^{\circ} \mathrm{C}$ in the dark. And then, spermatozoa were washed by centrifugation with $1 \mathrm{~mL}$ of $1 \mathrm{x}$ dilution buffer at $100 \times \mathrm{g}$ for $10 \mathrm{~min} 2$ times. Sperm cells were resuspended with mTCM 199 and $100 \mu \mathrm{L}$ of a semen sample $\left(1 \times 10^{6}\right.$ sperm cells/well) were added to a 96-well plate. Fluorescence was detected with a microplate fluorometer (Gemini Em; Molecular Devices, Sunnyvale, CA, USA) and analysed using SoftMax Pro 5 (Molecular Devices).

\section{Levels of intracellular reactive oxygen species (ROS)}

To determine the intracellular ROS level, the oxidationsensitive fluorescent dye DCFDA (Abcam, Cambridge, MA, USA) was used as described in our previous study [31]. The semen sample was centrifuged at $100 \times g$ for $10 \mathrm{~min}$, and the sperm pellet was resuspended in $1 \mathrm{~mL}$ of DCFDA. After $30 \mathrm{~min}$ of incubation at $37^{\circ} \mathrm{C}$ in an atmosphere of $5 \% \mathrm{CO}_{2}$, the sample was washed with $1 \mathrm{x}$ buffer solution and resuspended in $1 \mathrm{x}$ supplemental buffer. Fluorescence was detected using a microplate fluorometer (Gemini Em; Molecular Devices, Sunnyvale, CA, USA) and calculated with SoftMax Pro 5 (Molecular Devices).

\section{Artificial insemination}

The study was carried out in a Youna pig farm located in Anseong, South Korea.. To eliminate individual differences, three to four boar semen samples were pooled and then divided into three to four vials according to number of sperm cells $\left(30 \times 10^{8} / 100 \mathrm{~mL}\right)$. Total twenty boars were used for the insemination. Multiparous (2-8 parity) sows were used for AI to eliminate fertility variation and the age range of inseminated sows was 18 to 48 month. Heat check was performed by backpressure test using hand within 5 days post-weaning. Two times AI were performed on day 1 and day 2 after semen storage in BTS on a total of 329 multiparous Youna sows following oestrus detection. First insemination was performed within $24 \mathrm{~h}$ of oestrus detection, and second insemination was completed after $24 \mathrm{~h}$ after first insemination. Pregnancy was detected twice by ultrasonography at 24 and 35 days after insemination. The number of sows inseminated with spermatozoa stored at $\mathrm{pH} 7.2$ and those inseminated with spermatozoa stored at $\mathrm{pH} 6.2$ on day 1 was 77 and 80 , respectively. On day 2, 83 and 89 sows were inseminated in the $\mathrm{pH} 7.2$ and $\mathrm{pH} 6.2$ groups, respectively.

\section{Statistical analysis}

Data were analysed using a two-way analysis of variance (ANOVA) with GraphPad Prism (Version 9.0; GraphPad Software Inc.). When data showed a normal distribution, comparison of the sperm functional parameters including motility, motion kinematics, sperm viability, ATP, MMP, and ROS level between group was conducted by Tukey's multiple comparison test. Otherwise, a MannWhitney test was used to analyse. Chi-square test was used to evaluate the difference in the farrowing rate between the pH6.2 and 7.2 groups inseminated on day 1 and day 2. Statistical significance was set at $P<0.05$, and data are expressed as mean \pm SEM.

\section{Abbreviations \\ BTS: Porcine semen extender; Al: Artificial insemination; $X$ : $X$-chromosome- bearing spermatozoa; Y: Y-chromosome-bearing spermatozoa; MMP: Mito- chondrial membrane potential; ANOVA: Analysis of variance; HYP: Hyperacti- vated spermatozoa; VSL: Straight line velocity; VAP: Average path velocity.}

\section{Acknowledgements}

Not applicable.

\section{Authors' contributions}

The article was mainly conceived and designed by YJ and MG. Experimental data were collected by DH, DY, and analysed by YJ and WK. The manuscript was mainly written by YJ, and edited by MSR and EOA. All the authors contributed to read and approved the final manuscript.

Authors' information: Department of Animal Science \& Technology and BET Research Institute, Chung-Ang University, Anseong, Gyeonggi-do 17546, Republic of Korea.

\section{Funding}

This research was supported by the Basic Science Research Program through the National Research Foundation of Korea (NRF-2020R1C1C1003380).

\section{Availability of data and materials}

All data generated or analysed during this study are included in this published article.

\section{Declarations}

Ethics approval and consent to participate

All procedures were performed according to the guidelines for the ethical treatment of animals approved by the Institutional Animal Care and Use Committee of Chung-Ang University, Seoul, Korea (Approval No. 2017-00018). Informed consent for the use of animals was obtained from the animal owners.

\section{Consent for publication}

Not applicable.

\section{Competing interests}

The authors declare that they have no competing interests. 
Received: 8 September 2021 Accepted: 16 November 2021

Published online: 26 November 2021

\section{References}

1. Kurtz S, Petersen B. Pre-determination of sex in pigs by application of CRISPR/Cas system for genome editing. Theriogenology. 2019;137:67-74.

2. Johnson LA, Rath D, Vazquez JM, Maxwell WM, Dobrinsky JR. Preselection of sex of offspring in swine for production: current status of the process and its application. Theriogenology. 2005;63(2):615-24.

3. Rorie RW. Effect of timing of artificial insemination on sex ratio. Theriogenology. 1999:52(8):1273-80.

4. Nemeth M, Millesi E, Siutz C, Wagner KH, Quint R, Wallner B. Reproductive performance and gestational effort in relation to dietary fatty acids in guinea pigs. J Anim Sci Biotechnol. 2017;8:28

5. James WH. A prediction on the sex ratios of piglets. J Theor Biol. 2001;209(1):1-2.

6. Soede NM, Nissen AK, Kemp B. Timing of insemination relative to ovulation in pigs: effects on sex ratio of offspring. Theriogenology. 2000;53(4):1003-11.

7. Rath D, Ruiz S, Sieg B. Birth of female piglets following intrauterine insemination of a sow using flow cytometrically sexed boar semen. Vet Rec. 2003:152(13):400-1.

8. Abeydeera LR, Johnson LA, Welch GR, Wang WH, Boquest AC, Cantley TC, et al. Birth of piglets preselected for gender following in vitro fertilization of in vitro matured pig oocytes by $X$ and $Y$ chromosome bearing spermatozoa sorted by high speed flow cytometry. Theriogenology. 1998;50(7):981-8.

9. Knox RV. The current value of frozen-thawed boar semen for commercial companies. Reprod Domest Anim. 2011;46(Suppl 2):4-6.

10. Garner DL. Flow cytometric sexing of mammalian sperm. Theriogenology. 2006;65(5):943-57.

11. You YA, Kwon WS, Saidur Rahman M, Park YJ, Kim YJ, Pang MG. Sex chromosome-dependent differential viability of human spermatozoa during prolonged incubation. Hum Reprod. 2017;32(6):1183-91.

12. Song WH, Mohamed EA, Pang WK, Kang KH, Ryu DY, Rahman MS, et al. Effect of endocrine disruptors on the ratio of $X$ and $Y$ chromosomebearing live spermatozoa. Reprod Toxicol. 2018;82:10-7.

13. You YA, Mohamed EA, Rahman MS, Kwon WS, Song WH, Ryu BY, et al. 2,3,7,8-Tetrachlorodibenzo-p-dioxin can alter the sex ratio of embryos with decreased viability of $Y$ spermatozoa in mice. Reprod Toxicol. 2018;77:130-6.

14. Yule TD, Montoya GD, Russell LD, Williams TM, Tung KS. Autoantigenic germ cells exist outside the blood testis barrier. J Immunol. 1988:141(4):1161-7.

15. Park YJ, Kwon KJ, Song WH, Pang WK, Ryu DY, Saidur Rahman M, et al. New technique of sex preselection for increasing female ratio in boar sperm model. Reprod Domest Anim. 2021;56(2):333-41.

16. Peinado J, Medel P, Fuentetaja A, Mateos GG. Influence of sex and castration of females on growth performance and carcass and meat quality of heavy pigs destined for the dry-cured industry. J Anim Sci. 2008;86(6):1410-7.

17. Bonneau M. Use of entire males for pig meat in the European Union. Meat Sci. 1998:49S1:S257-72.

18. Martinez-Macipe M, Rodriguez P, Izquierdo M, Gispert M, Manteca X, Mainau $\mathrm{E}_{\text {, et }}$ al. Comparison of meat quality parameters in surgical castrated versus vaccinated against gonadotrophin-releasing factor male and female Iberian pigs reared in free-ranging conditions. Meat Sci. 2016;111:116-21.

19. De Briyne N, Berg C, Blaha T, Temple D. Pig castration: will the EU manage to ban pig castration by 2018? Porcine Health Manag. 2016;2:29.

20. de Roest K, Montanari C, Fowler T, Baltussen W. Resource efficiency and economic implications of alternatives to surgical castration without anaesthesia. Animal. 2009;3(11):1522-31

21. DeJarnette JM, Nebel RL, Marshall CE. Evaluating the success of sexsorted semen in US dairy herds from on farm records. Theriogenology. 2009:71(1):49-58.

22. Chandler JE, Steinholt-Chenevert HC, Adkinson RW, Moser EB. Sex ratio variation between ejaculates within sire evaluated by polymerase chain reaction, calving, and farrowing records. J Dairy Sci. 1998;81(7):1855-67.
23. Park YJ, Kim J, You YA, Pang MG. Proteomic revolution to improve tools for evaluating male fertility in animals. J Proteome Res. 2013;12(11):4738-47.

24. Khatun A, Rahman MS, Pang MG. Clinical assessment of the male fertility. Obstet Gynecol Sci. 2018;61(2):179-91.

25. Rahman MS, Kwon WS, Pang MG. Prediction of male fertility using capacitation-associated proteins in spermatozoa. Mol Reprod Dev. 2017:84(9):749-59.

26. Park YJ, Battistone MA, Kim B, Breton S. Relative contribution of clear cells and principal cells to luminal $\mathrm{pH}$ in the mouse epididymis. Biol Reprod. 2017;96(2):366-75.

27. Rahman MS, Kwon WS, Ryu DY, Khatun A, Karmakar PC, Ryu BY, et al. Functional and proteomic alterations of F1 capacitated spermatozoa of adult mice following gestational exposure to bisphenol a. J Proteome Res. 2018;17(1):524-35.

28. Casper RF, Meriano JS, Jarvi KA, Cowan L, Lucato ML. The hypo-osmotic swelling test for selection of viable sperm for intracytoplasmic sperm injection in men with complete asthenozoospermia. Fertil Steril. 1996;65(5):972-6.

29. Pang MG, You YA, Park YJ, Oh SA, Kim DS, Kim YJ. Numerical chromosome abnormalities are associated with sperm tail swelling patterns. Fertil Steril. 2010;94(3):1012-20

30. Oh SA, Park YJ, You YA, Mohamed EA, Pang MG. Capacitation status of stored boar spermatozoa is related to litter size of sows. Anim Reprod Sci. 2010;121(1-2):131-8.

31. Rahman MS, Kwon WS, Lee JS, Kim J, Yoon SJ, Park YJ, et al. Sodium nitroprusside suppresses male fertility in vitro. Andrology. 2014;2(6):899-909.

\section{Publisher's Note}

Springer Nature remains neutral with regard to jurisdictional claims in published maps and institutional affiliations.
Ready to submit your research? Choose BMC and benefit from:

- fast, convenient online submission

- thorough peer review by experienced researchers in your field

- rapid publication on acceptance

- support for research data, including large and complex data types

- gold Open Access which fosters wider collaboration and increased citations

- maximum visibility for your research: over 100M website views per year

At BMC, research is always in progress.

Learn more biomedcentral.com/submissions 